\title{
DA/DA Alçaltıcı Tip Dönüştürücü Devresinin TS-EN 61000-3-2 Standardına Uyumlu Hale Getirilmesi
}

\author{
Ayşenur Özer ${ }^{1 *}$, Ersoy Kelebekler ${ }^{2}$

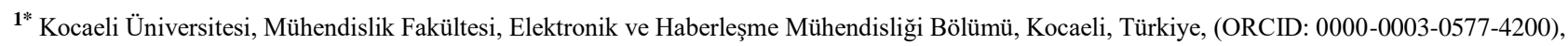 \\ 205103010@kocaeli.edu.tr \\ ${ }^{2}$ Kocaeli Üniversitesi, Uzunçiftlik Nuh Çimento MYO Fakültesi, Elektrik ve Enerji Bölümü, Kocaeli, Türkiye (ORCID: 0000-0002-9407-3926), ersoy@ kocaeli.edu.tr
}

(1st International Conference on Applied Engineering and Natural Sciences ICAENS 2021, November 1-3, 2021)

(DOI: 10.31590/ejosat.1009998)

ATIF/REFERENCE: Özer, A. \& Kelebekler, E. (2021). DA/DA Alçaltıc1 Tip Dönüştürücü Devresinin TS-EN 61000-3-2 Standardına Uyumlu Hale Getirilmesi. Avrupa Bilim ve Teknoloji Dergisi, (28), 653-659.

$\ddot{O} \mathbf{z}$

Bu çalışma kapsamında günümüzdeki bir çok elektronik cihazın enerji kaynağı olarak kullandığı doğru akım - doğru akım alçaltıcı dönüştürücü devresi TS-EN 61000-3-2 standardının gereklilikleri dikkate alınarak incelenmiştir. İlgili TS-EN standardı faz başına cihaz giriş akımı 16 amperden küçük olan cihazlar için harmonik akım sınır değerlerini tanımlar. Çalışmada, DA/DA alçaltıcı dönüştürücülerin şebekede oluşturduğu harmoniklerin TS-EN 61000-3-2 standardına uygun hale getirilecek şekilde azaltılması amaçlanmıştır. Bir DA/DA alçaltıcı dönüştürücünün şebekeye olan etkisinin ilgili TS-EN standardı kapsamında incelenebilmesi için DA/DA alçaltıcı dönüştürücü ve şebeke arasına bir köprü diyotlu AA/DA dönüştürücü eklenmiş̧ir. Ayrıca şebekenin elektrik devre modeli için $0.1 \Omega$ direnç ve $2 \mathrm{mH}$ endüktans alternatif akım kaynağına seri olarak bağlanmıştır. Kesikli akım çekerek şebekede istenmeyen harmoniklere neden olan DA/DA dönüştürücülerin bu etkilerini azaltmak veya ortadan kaldırmak amacıyla çeşitli süzgeç devreleri kullanılmaktadır. Bu çalışmada, alternatif akım kaynağında oluşan harmoniklerin akım kaynağına zarar vermesini önlemek ve elektromanyetik girişimleri ilgili TS-EN standardına uygun olarak azaltmak amacıyla alternatif akım kaynağı ile doğrultmaç devresi arasına seri bir endüktans eklenmiştir. Alçak geçiren süzgeç görevi yapan seri endüktansın farklı değerleri için devre benzetimi ve analizleri Matlab-Simulink programında gerçekleştirilmiştir. Çalışmada, seri endüktansın $2 \mathrm{mH}$ ile $17 \mathrm{mH}$ aralığındaki farklı değerleri için yapılan analiz sonuçları sunulmuştur ve ilgili TS-EN standardının gereklerini sağlayan filtre değeri belirlenmiştir.

Anahtar Kelimeler: DA/DA Alçaltıcı Dönüştürücü, Elektromanyetik Uyumluluk, Güç Elektroniği.

\section{DC/DC Buck Converter Compatible With TS-EN 61000-3-2 Standard}

\begin{abstract}
Within the scope of this study, the investigation of the direct current-direct current buck converter, which is used as an energy source for many electronic devices today, examined according to TS-EN 61000-3-2 standard. The standard defines harmonic current limit values for devices with device input current less than 16 Amps per phase. In the study, it is aimed to reduce the source harmonics of DC/DC buck converters to perform necesseries of TS-EN 61000-3-2 standard. Examine the effect of buck converter on the source, AC/DC converter was added between the buck converter and the source. For electrical circuit model of the source, $0.1 \Omega$ resistor and $2 \mathrm{mH}$ inductance are added to the circuit. Various filter circuits are used to reduce or eliminate the electromagnetic interference effects of DC/DC converters. Filter added between the source and the converter in order to prevent the harmonics occurring in the source from damaging the current source and to reduce electromagnetic interferences in accordance with standard. Circuit analysis for different values of series inductance acting as a low-pass filter were carried out in Matlab-Simulink. In the study, analysis results for series inductance values between $2-17 \mathrm{mH}$ are presented and the value of inductance providing necesseries of standard is determined.
\end{abstract}

Keywords: DC/DC Buck Converter, Electromagnetic Compatibility, Power Electronics.

* Corresponding Author: aysenurozer7058@gmail.com 


\section{Giriş}

Elektrik şebekelerinden alternatif akım dağıtımı yapılmasına rağmen günümüzdeki bir çok elektronik cihaz doğru akımla çalışmaktadır ve bu nedenle dönüştürücülere ihtiyaç duyulmaktadır. Aynı zamanda DA/DA dönüştürücü devreleri ile elektrik enerjisi kontrol altına alınmakta ve istenen çıkış gerilimi seviyesine uygun tasarımlar gerçekleştirilmektedir. DA/DA dönüştürücülerin temel kullanım alanı, devrenin girişindeki doğru akım ve gerilimi devrenin çıkışına bağlanacak olan sistemin beslemesini sağlayacak genlik seviyesine taşımaktır. Proje kapsamında tasarımı hedeflenen anahtarlamalı dönüştürücü alçaltıcı tiptedir. Alçaltıcı tip dönüştürücünün temel özelliği, girişine uygulanan yüksek değerdeki gerilimin devrenin çıkışında daha düşük olarak elde edilmesidir.

Temel olarak alçaltıcı tip DA/DA dönüştürücüler; DA kaynağ1, diyot, transistör, kapasitör, indüktör ve yük direncinden oluşmaktadır. Anahtarlama elemanı olarak kullanılan transistörün devreden kesikli akım çekmesinden kaynaklanan etkileri, devre girişindeki harmoniklerdir. Harmoniklerin devrede bulunan kaynağa ve elektrik sistemine bozucu etki oluşturması kontrol altına alınması gerektiğinin bir göstergesidir. Harmoniklerin incelenebilmesi için alçaltıcı DA/DA dönüştürücünün girişine AA/DA dönüştürücü devresi eklenmiştir. Tasarlanan devrelerin elektromanyetik uyumluluğunun test edilmesi amaciyla besleme kaynağına aktarılan harmonik akımların TS-EN 61000-3-2 standardının sınır değerlerinin altında olması beklenmektedir. İlgili standart faz başına cihaz giriş akımı 16 Amper dahil ve 16 Ampere kadar olan dört sınıfa ait cihazları kapsamaktadır. Sınıf A dengeli 3 fazlı cihaz, evde kullanılan aletler, akkor lambalar için alçaltıcılar, taşınabilir olmayan aletleri kapsamaktadır; Sınıf B taşınabilir cihazlar, profesyonel olmayan ark kaynak cihazları; Sınıf C aydınlatma cihazları; Sınıf D ise kişisel bilgisayar ve ekranlar1, televizyon uydu alıcıları, kompresör motoru kontrolü için değişken hızlı sürücülü buzdolapları ve dondurucu cihazları kapsamaktadır. Ayrıca Sinıf D cihazlarının gücü 600 Watt'a eşit ya da daha düşük olmalıdır. 600 Watt'tan daha düşük güçle çalışan ve devre akımının 16 Amper'den daha düşük olması nedeniyle ilgili devrenin, TSEN 61000-3-2 standardında belirtildiği üzere Sınıf D grubuna ait olduğu tespit edilmiştir. İlgili standart elektromanyetik uyumluluk standardıdır, temel harmonik dışındaki bazı harmoniklerin Sınıf D grubunun sınır değerlerinin altında olması gerekmektedir. Bu sınır şartlarını sağlayan cihazlar ilgili standarda göre elektromanyetik uyumlu olarak adlandırılmaktadır. Bir cihazın elektromanyetik uyumlu olabilmesi için hem çevredeki cihazlara bozucu etkilerinin olmaması hem de çevredeki cihazların bozucu etkilerine karşı alıngan olmaması gerekmektedir. $\mathrm{Bu}$ devrenin harmonik etkilerinden kaynaklanan iletim yollu elektromanyetik girişiminin önlenebilmesi için devrenin girişine alçak geçiren süzgeç yapısı eklenmiştir. Temel olarak süzgeç yapısı devreye seri olarak bağlanan indüktörden oluşmaktadır. Ensüktansın değerindeki değişimlerin harmoniklerdeki etkileri incelenmiş ve ilgili standartta belirtilen harmonik değerlerinin altında tutulması sağlanmıştır. Sonraki bölümlerde alçaltıcı tip DA/DA dönüştürücülerin teorik alt yapısından, temel yapıdaki bir dönüştürücü devresinin ve harmonik ölçümü için tasarlanan devrenin analizlerinden, ilgili standardın Sınıf D harmonik akımlar ile igili sınır değerlerini sağlaması için devreye eklenen süzgeç yapısından ve ilgili TS-EN 61000-32 standardının harmonikler için sınır değerlerinin devrede oluşan harmoniklerle kıyaslarından bahsedilmiştir.

\section{Materyal ve Metot}

Anahtarlamalı alçaltıcı tip DA/DA dönüştürücü devreleri sabit ya da ayarlanabilir çıkış DA gerilimi üretmek amaçlı kullanılmaktadır. Anahtarlama elemanı transistör olan gerilim kaynaklarının doğrusal yapıda olanlara göre üstünlükleri vardır. $\mathrm{Bu}$ üstünlükler, anahtarlama elemanlarının darbe genişlik modülasyonu (PWM) ile kontrol edilebilmesinden ve yüksek frekanslarda çalışabilmesinden kaynaklanan yüksek verim, yüksek güç yoğunluğu ve hızlı geçiş cevabıdır. Anahtarlama elemanı bulunduran DA/DA çeviriciler temel olarak seri olarak bağlanan endüktansın enerji aktarımına bağlı olarak çalışmaktadır. Anahtarlama elemanı olarak kullanılan transistörler, güç kaynağından kesikli akım çekip enerji depolama özellikleri bulunan endüktans ve kapasitans aracılığı ile çıkış yüküne enerji aktarırlar. Transistör iletimde iken endüktansta depolanan enerji diyot iletimde olduğunda çıkış yüküne aktarılmaktadır. Doğrusal güç kaynaklarına göre üstünlükleri dolayısıyla anahtarlamalı devreler çokça tercih edilmektedir. Endüstrideki ihtiyaçlara göre daha yüksek verim, yüksek güç yoğunluğu istendiği durumlar için frekans yükseltilerek bu kazançlar sağlanabilirken frekansın yükselmesi anahtarlama kayıplarına ve elektromanyetik girişime neden olmaktadır. Oluşabilecek elektromanyetik girişim gürültüleri kontrol yöntemleri ve yumuşak anahtarlama teknikleriyle önlenebilmektedir.

\section{Araştırma Sonuçları ve Tartışma}

Tasarım aşamasında ilk olarak kaynaktan alınan bir devre ile alçaltıcı tip DA/DA devresi Matlab-Simulink programında oluşturulmuş, daha sonra bu devre analiz edildiğinde istendiği gibi girişine uygulanan 50 Volt gerilimini çıkışında 20 Volt değerine düşürebildiği gözlemlenmiştir. Tüm devre elemanları program kütüphanesinde sirasiyla Simscape, Power Systems alt kütüphanesinde bulunan Specialized Technology kütüphanesindeki devre elemanları kullanılarak oluşturulmuştur. Temel yapıdaki alçaltıcı dönüştürücü devre Şekil 1'de gösterildiği gibi; DA gerilim kaynağı, transistör, diyot, endüktans, kapasitans ve yük geriliminden oluşmaktadır. Transistör elemanı örnekleme zamanı $5 \mu \mathrm{s}$ olacak biçimde ayrık zamanlı powergui tanımlanmış, transistörün kap1(gate) girişine darbe üreteci eklenerek beslemesi sağlanmıştır. Transistörün anahtarlaması $20 \mathrm{KHz}$ frekansında ve darbe genişlik modülatörünün \% 40 doluluk oranıyla çalışması için darbe üretecinin darbe genişlik oranı 0.4 olarak girilmiştir. Devrede kullanılan elemanların değerleri; güç kaynağ $0.1 \Omega$, endüktans $400 \mu \mathrm{H}$, kapasitans $100 \mu \mathrm{F}$, yük direnci 20 $\Omega$ 'dur. 


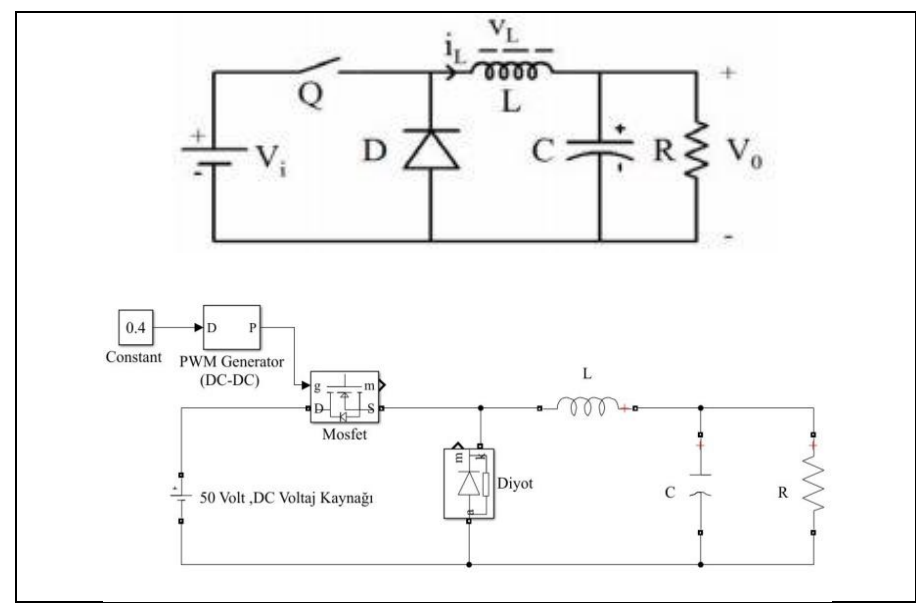

Şekil 1. (a)Temel yapıdaki alçaltıcı tip DA/DA dönüştürücü devresi, (b) DA/DA dönüştürücü devresi Matlab-Simulink benzetimi

Temel yapıdaki alçaltıcı tip DA/DA dönüştürücü devresi Şekil 1(a) ve bu devrenin Matlab Simulink programında benzetimi Şekil 1(b)'de gösterilmiştir. Devre analiz edildiğinde çıkış yük direnci üzerinde görülen gerilim grafiği Şekil 2'de gösterildiği gibi devrenin çalışmaya başladığı zamandan 0.01 saniye sonra 20 volt değerinde sabitlenmiştir. Çıkış direnci $20 \Omega$ ve çıkış gerilimi 20 volt olduğundan dolayı yük direncinin üzerinden geçen akım 1 amperdir.

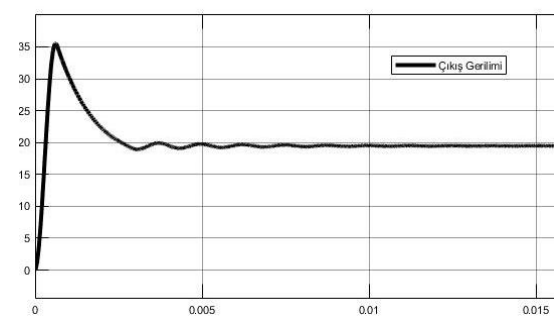

Şekil 2. Yük direnci uçları arasında ölçülen gerilim grafiği

Devrenin alçaltıcı dönüştürücü devresinin istenildiği gibi çalıştığı analiz edildikten sonra projenin asıl çalışılma amacı olan harmonik incelenmesi aşamasına geçilmiştir. $\mathrm{Bu}$ tasarım aşamasında Şekil 1'de gösterilen devrenin DA güç kaynağı çıkartılarak yerine AA/DA dönüştürücü devresi eklenmiş̧ir, bu devre temel olarak alternatif akım üreten güç kaynağından, güç kaynağının iç direncinden, seri bağlı bir endüktans ve tam doğrultucu olarak görev yapan köprü diyottan oluşmaktadır. $\mathrm{AA} / \mathrm{DA}$ ve $\mathrm{DA} / \mathrm{DA}$ dönüştürücü devrelerinin arasında paralel bağlı bir kapasitans bulunmaktadır. Şekil 3 'te gösterildiği gibi oluşturulan devredeki $\mathrm{AA} / \mathrm{DA}$ dönüştürücü devresindeki elemanların değerleri; gerilim kaynağı şebeke sinyalini temsil etmektedir bu nedenle $50 \mathrm{~Hz}$ frekansında, tepe değeri 324 Volt olan bir sinüzoidal işaret üretmektedir. Gerilim kaynağı tarafinda bir transformatörün elektrik devre modeli için seri direnç ve endüktans AC kaynak ve doğrultmaç arasına eklenmiştir. Seri kaynak direnci $0.1 \Omega$, seri endüktans $2 \mathrm{mH}$ 'dir.

Doğrulma amaçlı kullanılan yapıda transformatör, diyot ve kapasitans bulunmaktadır. Tam dalga doğrultucu yapısının çıkışında dalgalanmaları azaltmak ve daha kararlı DA elde edebilmek için süzgeçleme amaçlı kullanılan paralel kapasitans değeri $690 \mu$ Folarak seçilmiştir.

Devrenin alçaltıcı tip DA/DA dönüştürücü kısmında ise transistör, diyot, endüktans, kapasitans ve yük direnci bulunmaktadır. Powergui sürekli zaman olarak ayarlandığından transistörün kap1 ucuna gönderilmesi gereken işaret darbe genişlik modülasyonu (PWM) üreteci ile sağlanmıştır. Girişe uygulanan AA 324 Volt şebeke sinyalinin çıkışa DA 100 Volt olarak aktarılması amaçlanmıştır. Çıkış geriliminin 100 Volt'ta sabitlenebilmesi için PWM doluluk boşluk oranı süzgeçsiz ve değiş̧en süzgeçli devre yapıları için değişkenlik göstermiştir. Bu çalışmanın temel amacı kullanılan denetleyici yapısından bağımsız olarak alçaltıcı DA/DA dönüştürücüde devresinin şebekede neden olduğu harmonikleri TS-EN 61000-3-2 standardı çerçevesinde azaltmaktır. Bu nedenle alçaltıcı DA/DA devresinde herhangi bir denetleyici yapısı kullanılmamışı̧ı. Süzgeçsiz devre için PWM doluluk oranı \% 32.2 olarak belirlenmiş bu değer devre elemanı girişine eklenen sabit sayı değeri üreten devre elemanı ile sağlanmıştır. Şekil 3 'te gösterildiği gibi giriş ve çıkışlardaki akım ve gerilim değerlerinin kıyaslanabilmesi için akımölçer ve gerilimölçer eklenmiştir. Giriş akımını gözlemleyebilmek için $2 \mathrm{mH}$ endüktansının sağına akımölçer, doğrulmaç devresinin gerilimini gözlemleyebilmek için köprü doğrultucunun sağına ve çıkış gerilimi için yük direncinin sağına gerilimölçer yapıları eklenmiştir. Her bir ölçüm aleti daha sonra 3 girişli Scope'a bağlanmıştır.

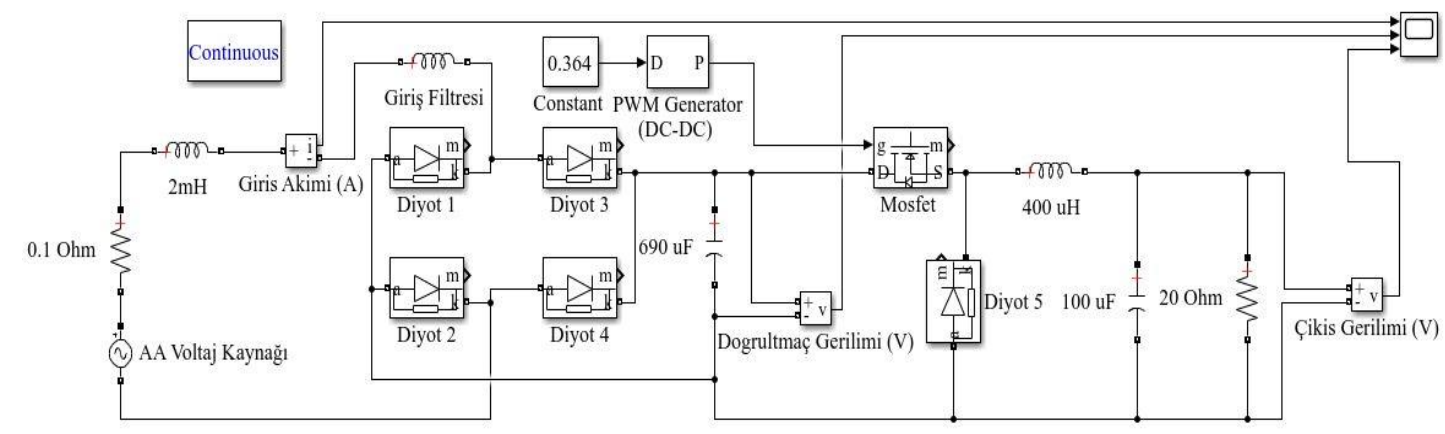

Şekil 3. Harmonik ölçümü için tasarlanan dönüştürücü devre şeması 
Şekil 3'teki verilen devrede giriş filtersi endüktans değeri sıfir olduğu durum (süzgeçsiz devre) için analiz sonuçları Şekil 4 'te verilmiştir. Analiz sonuçları şekilde, mavi renk ile giriş akımının, kırmızı ile doğrultmaç geriliminin, sarı ile buck konvertör çıkış geriliminin zamana göre değişimleri olarak verilmiştir. Kaynaktan kesikli akım çekildiği için şekilde mavi ile verilen giriş akımı dalga şeklinde süreksizlik meydana gelmektedir. Giriş akımının 0.15 ve 0.2 saniye arasındaki zamana göre değişimi Şekil 4'te alt figürde detaylı olarak gösterilmektedir. Şebekeden çekilen bu kesikli akım hamoniklere neden olmaktadır. TS-EN 6100-3-2 standardı faz başına cihaz giriş akımı 16 Amperden küçük olan cihazlar için harmonik akım sınır değerlerini tanımlar ve piyasada kullanıma girecek cihazları sınırlar içinde kalmaya zorunlu kılar. Çalışmanın devamında oluşturulan devre ilgili standart gereklilikleri çerçevesinde incelenecektir.

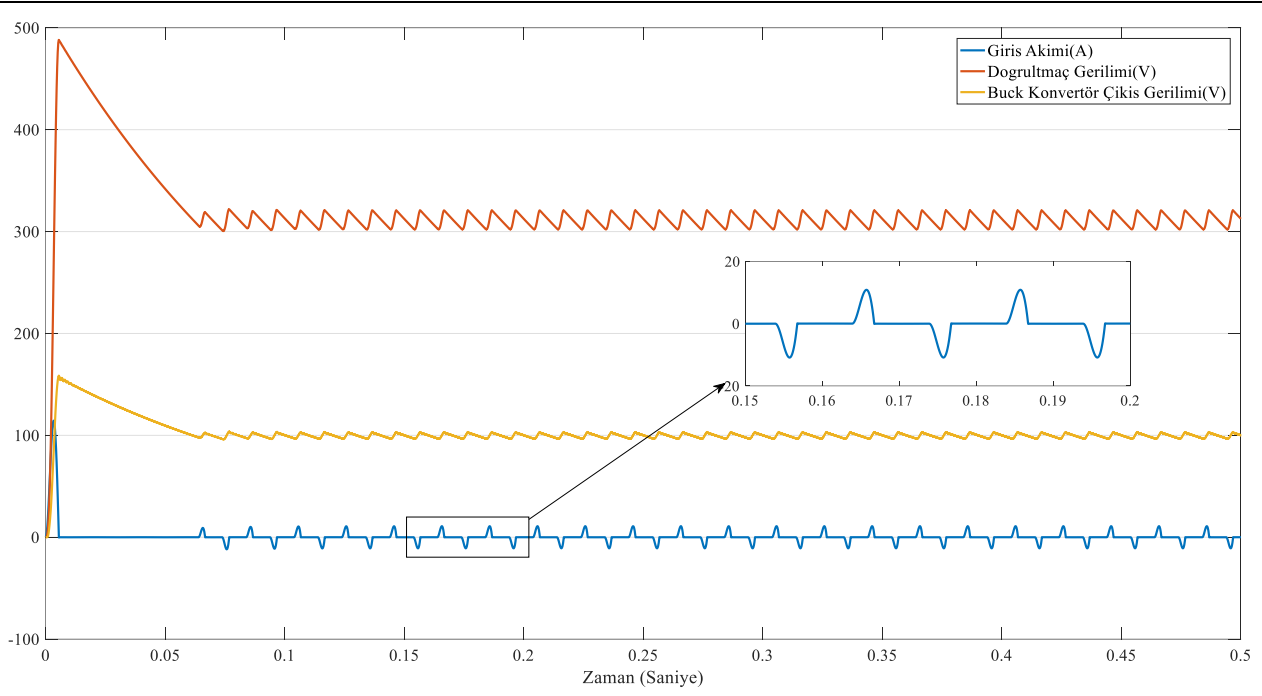

Şekil 4. Akım ve gerilim değişimleri

Şekil 4 'te görüldüğü gibi alçaltıcı dönüştürücü çıkış gerilimi 100 volttur ve gerilim grafiğinde dalgalılık bulunmaktadır, çıkış geriliminin yaptığı salınımda en yüksek gerilim değeri 103.4 Volt, en düşük gerilim değeri 96.6 Volt'tur. Çıkıştaki bu dalgalılık oranı yüzde olarak Denklem 1 kullanılarak hesaplanır ve \%6.5'ten daha az olması istenir. Denklem 1 kullanılarak süzgeçsiz devrenin dalgalılık değeri \% 2.4 olarak hesaplanmıştır.

$$
\% \text { ripple }=\frac{\text { Dalgalanmanın } r m s(\text { etkin }) \text { değeri }}{\text { İşaretin ortalama değeri }} \times 100 \quad 1
$$

Çalışmada bu noktadan itibaren şebekeden beslenen ve $\% 32.2$ doluluk oranına sahip bir PWM sinyal ile sürülen $100 \mathrm{~V}$ çıkış gerilimine sahip alçaltıcı tip DA/DA dönüştürücünün şebekede oluşturduğu harmonikleri belirlemek ve TS-EN6100-3-2 standardının gereklerini sağlayıp sağlamadığını saptamak amacıyla devrenin giriş akım sinyali için harmonik analizi yapılmıştır. TS-EN 61000-3-2 elektromanyetik uyumluluk standardıdır, elektrik şebekesine bağlanan cihazların elektrik kaynağında neden oldukları harmonik akımlarının sınırlarını tanımlar. İlgili standart ses cihazları ve akkor lamba kısıcılarını kapsayan Sınıf A, taşınabilir aletler ve ark kaynak cihazlarını kapsayan Sınıf B, aydınlatma cihazlarını kapsayan Sınıf C ve son olarak kişisel bilgisayar, bilgisayar ekranları, televizyon alıcıları, kompresör motoru kontrolü için değişken hızlı sürücülü buzdolab1 veya dondurucuları kapsayan Sinıf D olarak gruplandırılmaktadır. Ayrıca Sınıf D gücü 600 Watt'a eşit ya da daha düşük, faz başına giriş akımı 16 Amper'e kadar olan elektronik ve elektrikli cihazları kapsamaktadır. Bilgisayar programında tasarımı ve analizi gerçekleştirilen devrenin Sınıf D'ye ait olduğu, harmonik akım ölçümlerinin ilgili standardın ilgili sınıfına ait olan sınır değerlerini sağlaması gerekmektedir. Şekil 5'te TS-EN 61000-3-2 standardına ait Sınıf D cihazları için belirlenmiş olan harmonik değerleri verilmiştir.

\begin{tabular}{|c|c|c|}
\hline Harmonik mertebe & $\begin{array}{c}\text { Watt başına azami izin } \\
\text { verilebilen harmonik akım } \\
\text { mAW }\end{array}$ & $\begin{array}{c}\text { Azami izin verilebilen harmonik } \\
\text { akım }\end{array}$ \\
$\mathbf{n}$ & 3,4 & 2,30 \\
\hline 3 & 1,9 & 1,14 \\
7 & 1,0 & 0,77 \\
9 & 0,5 & 0,40 \\
11 & 0,35 & 0,33 \\
$13 \leq n \leq 39$ & $\frac{3,85}{n}$ & Çizelge 1'e bakılmalıdır. \\
(sadece tek harmonikler) & & \\
\hline
\end{tabular}

Şekil 5. TS-EN 61000-3-2 standardı Sinıf D harmonik akım sinır değerleri

Alçaltıcı tip DA/DA dönüştürücü devresinin şebekede neden olduğu bozulmaları incelemek için giriş akım sinyalinin Fourier analizi yapılmıştır. Bu işlem powergui'nin içinde bulunan FFT (Hızlı Fourier Dönüşümü) analizi aracı kullanılarak yapılmıştır. Şekil 4'te verilen giriş akımı sinyalinin 0.1 ile 0.2 saniye aralığındaki beş periyodu için FFT analizi elde edilmişsir. $\mathrm{Bu}$ incelemeye göre TS-EN 61000-3-2 standardının Sınıf D grubuna ait olan cihazlar için belirlediği harmonik sınır değerleri ile devrede oluşan harmonikler karşılaştırıldığında, standardın Şekil 5 'te sunulan 3. Harmonik için 2.3 Amper, 5. Harmonik için 1.14 Amper, 7 Harmonik için 0.77 Amper sınır değerlerine göre kıyaslandığında tasarlanan devrede 3. Harmonik 3.02 Amper, 5. Harmonik 2.3 Amper, 7. Harmonik değerinin 1.48 Amper olarak elde edilmiştir. İlgili harmonikler sırayla karşılaştırıldığında devredeki harmoniklerin standardın belirlediği sınırların üzerinde değerlerde olduğu görülmektedir. Dolayısıyla ilgili standarda uyabilmek için oluşturulan devrenin harmoniklerinin azaltılması zorunludur. Kesikli akım çekerek şebekede istenmeyen harmoniklere neden olan DA/DA dönüştürücülerin bu etkilerini azaltmak veya ortadan kaldırmak amacıyla çeştili 
süzgeç devreleri kullanılmaktadır. Bu çalışmada, devrenin güç kaynağına kesikli akım çekilmesinden kaynaklı gönderilen istenmeyen harmonikleri bastırmak amacıyla devrede kaynak ile doğrultmaç devresi arasına seri bir endüktans eklenmiştir. Giriş süzgeci olarak kullanılan bu seri endüktansın farklı değerleri için devrenin tekrar analizleri gerçekleştirilmiştir ve sonuçlar sunulmuştur. Girişe bağlanan endüktans akımda faz kaymasına neden olduğu için devre girişinden fazladan reaktif güce neden olur. İlgili reaktif güç nedeniyle kaynakta ki görünür gücü büyür. $\mathrm{Bu}$ da akımın artmasına neden olur. Özellikle yüksek akım değerleri için akım artışı iletim yollarında kaybın artmasına neden olur. İlgili gerekçelerden dolayı standardı sağlayacak en küçük değerli endüktansı saptamak önemlidir. Gereğinden büyük seçilecek bir endüktans kaynak tarafında görünür güçün artmasına, maliyet artışına ve endüktansın fiziksel boyutunun da artması nedeniyle devrenin fiziksel boyutlarının büyümesine neden olacaktır. Ek olarak analizlerde, değişen her bir giriş endüktansı için devrenin çıkışında meydana gelecek değişimler DA/DA dönüştürücü sürücüsü PWM doluluk oranı değiştirilerek ortadan kaldırılmış ve çıkışta elde edilen yeni dalgalılık oranları hesaplanmıştır. Giriş süzgeçinin harmonikleri azaltarak sağladığ diğer bir kazanç ise toplam harmonik bozulmadaki (THD) azalmadır. Giriş filtresinin her bir farklı empedans değeri için THD değerleri elde edilmiştir. Toplam harmonik bozulma
Denklem 2'de gösterildiği gibi harmoniklerin temel harmoniğe oranlarının karelerinin toplamının karekökü ile hesaplanmaktadır.

$$
T H D=\sqrt{\sum_{h=2}^{n}\left(\frac{I_{h}}{I_{1}}\right)^{2}}
$$

İlgili denklemde yer alan $h$ harmoniğin numarasını ve $n$ ise hesaplamada kullanılacak harmonik sayısını göstermektedir. TSEN 61000-3-2 standardının tek harmonikleri için sınır değerleri, süzgeçsiz devre ve farklı endüktans değerleri için süzgeçli devre tek harmoniklerin akım değerleri, toplam harmonik bozulma (THD), çıkış gerilimindeki en yüksek, en düşük değerler ve çıkış geriliminin dalgalılık oranı Tablo 1'de verilmiştir. Ayrıca, filtresiz ve farklı endüktans değerlerine sahip süzgeçli devre yapısının çıkış geriliminin 100 Volt değerinde kalmasını sağlayan PWM doluluk oranları tabloda sunulmuştur. Değişen endüktans filtrelerine göre PWM oranı, harmoniklerin genlikleri, THD değeri ve çıkış gerilimin salınımı sonucu maksimum ve minimum genlik değerleri, dolayısıyla dalgalılık yüzdesi değişkenlik göstermektedir.

Tablo 1 Süzgeç değişiminin harmoniklerdeki, toplam harmonik bozulmadaki ve çıkıs gerilimindeki etkisi

\begin{tabular}{|c|c|c|c|c|c|c|c|c|c|}
\hline $\begin{array}{l}\text { Standart } \\
\text { ve } \\
\text { Filtreler }\end{array}$ & $\begin{array}{l}\text { Duty } \\
\text { Cycle }\end{array}$ & $\begin{array}{c}3 . \\
\text { Harmonik }\end{array}$ & $\begin{array}{c}5 . \\
\text { Harmonik }\end{array}$ & $\begin{array}{c}7 . \\
\text { Harmonik }\end{array}$ & $\begin{array}{c}9 . \\
\text { Harmonik }\end{array}$ & $\begin{array}{c}\text { THD } \\
(\%)\end{array}$ & $\begin{array}{l}\text { Maksimum } \\
\text { Gerilim(V) }\end{array}$ & $\begin{array}{c}\text { Minimum } \\
\text { Gerilim } \\
\text { (V) }\end{array}$ & $\begin{array}{c}\text { Dalgalılık } \\
(\%)\end{array}$ \\
\hline $\begin{array}{c}\text { TS-EN } \\
\text { 61000-3-2 } \\
\text { Standardl }\end{array}$ & & 2.3 & 1.14 & 0.77 & 0.4 & 15 & - & - & - \\
\hline Süzgeçsiz & 0.322 & 3.02 & 2.3 & 1.48 & 0.76 & $\begin{array}{c}122.0 \\
5\end{array}$ & 103.4 & 96.6 & 2.4 \\
\hline $2 m H$ & 0.33 & 2.88 & 1.91 & 0.95 & 0.35 & $\begin{array}{c}104.0 \\
8\end{array}$ & 103.3 & 96.7 & 2.33 \\
\hline $5 \mathrm{mH}$ & 0.335 & 2.7 & 1.51 & 0.55 & 0.29 & 90.45 & 102.8 & 96.8 & 2.12 \\
\hline $10 \mathrm{mH}$ & 0.351 & 2.52 & 1.09 & 0.33 & 0.29 & 77.17 & 103.4 & 97.5 & 2.07 \\
\hline $15 m H$ & 0.36 & 2.34 & 0.81 & 0.31 & 0.23 & 68.92 & 103 & 97.1 & 2.07 \\
\hline $16 \mathrm{mH}$ & 0362 & 2.31 & 0.77 & 0.31 & 0.21 & 67.54 & 103 & 97.1 & 2.07 \\
\hline $17 \mathrm{mH}$ & 0.364 & 2.28 & 0.73 & 0.32 & 0.2 & 66.22 & 103.1 & 97.2 & 2.07 \\
\hline
\end{tabular}

Kaynaktan kesikli akım çekilmesinden, endüktans ve kapasitansların enerji depolama özelliklerinden kaynaklanan etkiler çıkış gerilimi ve çıkıştaki yük direnci üzerinden geçen akımda salınımlara ve girişteki gerilim kaynağında harmoniklere sebep olmaktadır. $\mathrm{Bu}$ harmonikler giriş süzgeci olarak kullanılan endüktans değeri $2 \mathrm{mH}$ değerinden $17 \mathrm{mH}$ değerine kadar yükseltilerek ortadan kaldırılmaya çalışılmıştır. Yukarıda bahsedildiği gibi Şekil 4'te akım-gerilim sinyalleri sunulan süzgeçsiz devrenin analizi ilgili standart değerleri ile karşılaştırıldığında sınır değerleri aştığı saptanmıştır. Ayrıca süzgeçsiz devre için THD \%122.05 olarak elde edilmiştir. e-ISSN: 2148-2683
Sonuç olarak kesikli akım çekmesinden kaynaklanan harmoniklerin devrenin gerilim kaynağına bozucu etkileri olduğundan ve bu harmoniklerin standardın gerekliliklerini karşılamamasından ilgili sınır değerlerine düşürülmesi zorunludur. Devreye süzme amaciyla bağlanan seri endüktans değerleri sirasiyla $2 \mathrm{mH}, 5 \mathrm{mH}, 10 \mathrm{mH}, 15 \mathrm{mH}, 16 \mathrm{mH}$ ve 17 $\mathrm{mH}$ dir. Her bir değer için giriş akımı sinyalinin Fourier analizi yapılarak standardın tek harmonik sınırlarını karşılayıp karşılamadıkları incelenmiştir. Analizler sonucunda ilgili standardın sınır değerlerini ilk karşılayan süzgeç değeri $17 \mathrm{mH}$ olarak elde edilmiştir. Endüktans değerinin yükselmesine bağlı 
olarak THD’nin de düştüğü tablodan verilen sonuçlardan açıkça görülmektedir. Yapılan analizler sonucunda endüktans değerinin artmasına bağlı olarak, devreden kesikli akım çekilmesinden kaynaklanan ve devrenin kaynağına bozucu etkileri olan harmoniklerin düştüğü gözlemlenmiş olmasına rağmen alçak geçiren süzgeç görevi gören endüktansın değerinin diğer belirleyici unsuru da endüktif reaktanstır. Süzgeç olarak kullanılan endüktans değeri yükseldikçe THD ve tek sayıdaki harmonikler düşmesine rağmen endüktif reaktans ve kaynaktaki görünür güç artmaktadır. Bu da akımın artmasına neden olur. Artan akım iletim yollarında kaybın artması sonucunu doğurur. $\mathrm{Bu}$ sebeple yapilan analizlerle elde edilen ve Tablo 1 'de gösterilen veriler sonucunda ilgili standardın akım harmonikleri sınır değerlerini sağlayan en küçük endüktans değeri olan $17 \mathrm{mH}$ seçilmiştir. TS-EN 61000-3-2 standardının Sınıf D grubuna ait olan cihazlar için belirlediği harmonik sınır değerleri ile alçak geçiren süzgeç yapısı eklenmiş devrede oluşan harmonikler karşılaştırıldığında, standardın 3. Harmonik için 2.3 Amper, 5. Harmonik için 1.14 Amper, 7 Harmonik için 0.77 Amper, 9. Harmonik için 0.4 Amper sınırlarında olduğu ve tasarlanan devredeki 3. Harmonik 2.28 Amper, 5. Harmonik 0.73 Amper, 7. Harmonik 0.32 Amper ve 9. Harmonik değerinin 0.2 Amper oluğu gözlemlenmiştir. İlgili harmonikler sırasıyla karşılaştırıldığında devredeki harmoniklerin standardın sınırların altında değerlerde olduğu ve ilgili standardın gerekliliklerini sağladığı belirlenmiştir. Şekil 6'da gösterildiği gibi süzme işleminde en uygun değer olarak belirlenen $17 \mathrm{mH}$ endüktansı devreye alçak geçiren süzgeç olarak eklendiğinde oluşan harmonikler, ilgili standart ve süzgeçsiz devre yapısı ile karşılaştırılmıştır. İlk sütun ilgili standardı göstermektedir. İkinci sütun süzgeçsiz devrede oluşan harmonikleri gösterirken üçüncü sütun süzgeçli devreyi temsil etmektedir.

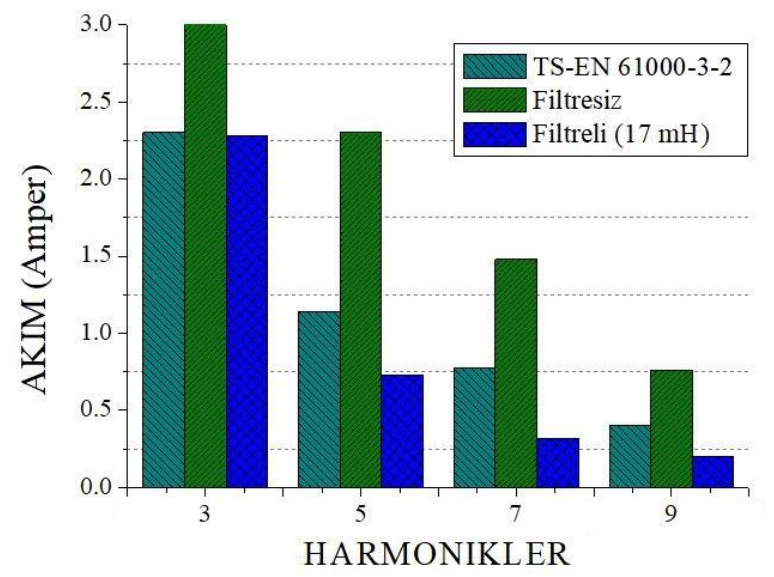

Şekil 6. Standart sınır değerleri ile süzgeçli ve süzgeçsiz devrelerin harmoniklerinin karşılaştırılması

Tüm değerler kıyaslandığında süzgeçsiz devrenin harmoniklerinin ilgili standart sınır değerlerini sağlamadığı, 17 $\mathrm{mH}$ değerinde giriş süzgeci olarak kullanılacak bir endüktans ile TS-EN 61000-3-2 standardının gerektirdiği sınır koşulların sağladığı gösterilmiştir. Süzgeçsiz ve süzgeçli devre durumunda giriş akımının nasıl değiştiği Şekil 7'de verilmiştir.

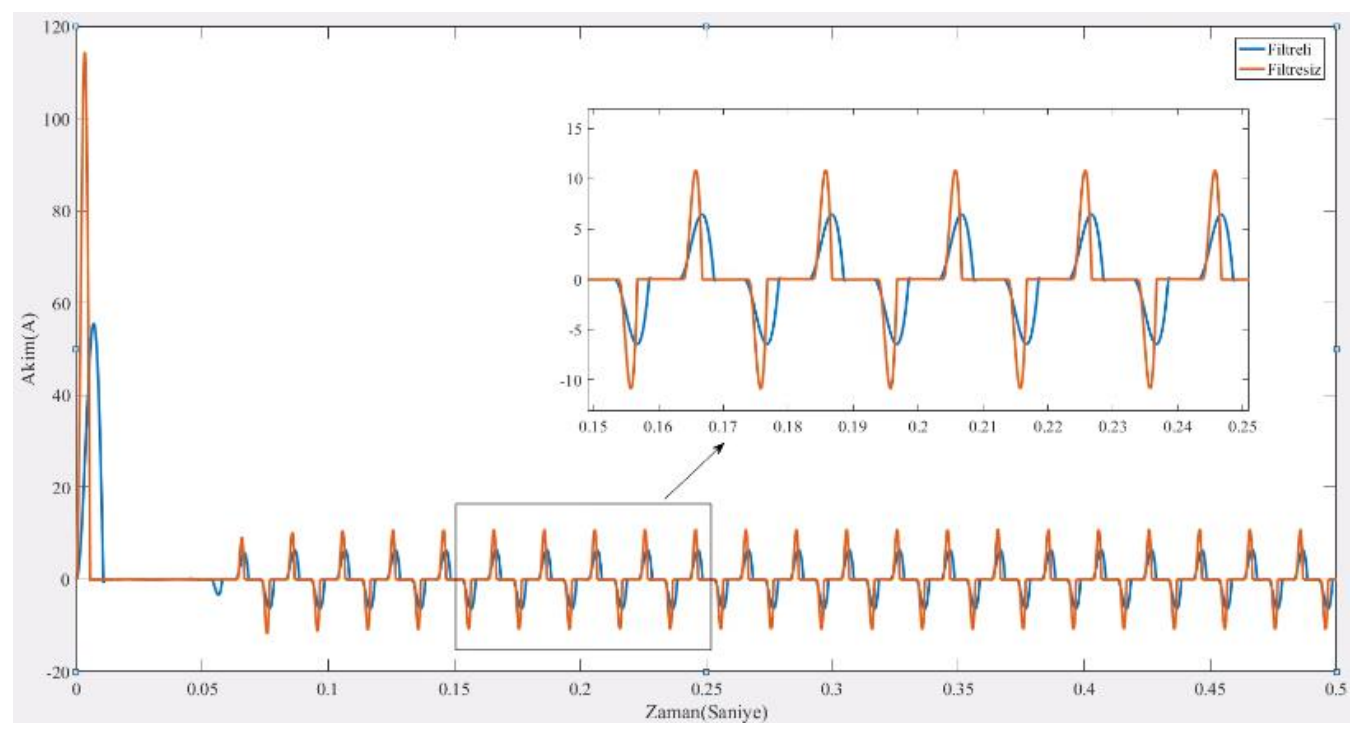

Şekil 7. Süzgeçsiz ve süzgeç uygulanmış devrelerin giriş akımlarının zamana göre değişimi

Şekilde kırmızı renk ile verilen sinyal süzgeçsiz devrenin giriş akımının zamana göre değişimini, mavi renk ile verilen sinyal ise endüktansı $17 \mathrm{mH}$ olan alçak geçiren süzgeç uygulanmış devrenin giriş akımının zamana göre değişimini göstermektedir. Süzgeçsiz devrenin giriş akımı ile endüktans değeri $17 \mathrm{mH}$ olan alçak geçiren süzgeçli devrenin giriş akımları karşılaştırıldığında akımın maksimum değerinde düşüş olduğu görülmektedir. İki sinyalin etkin değerleri yaklaşık olarak eşit olmakla birlikte süzgeç kullanılması durumunda akımın maksimum değerinde düşme ve kaynaktan zaman ekseninde daha uzun süreye yayılmış bir akım çekilmesi sağlanmıştır. Sonuç olarak kesikli akım akışı zamana yayılarak yumuşatılmıştır. Şekil 7 alt figürde
0.15 ile 0.25 saniye aralığı daha detaylı incelendiğinde süzgeçsiz devrenin giriş akımının daha keskin değişiminin olduğu, süzgeç uygulanmış devrenin giriş akımının değişiminin zamana daha çok yayıldığı görülmektedir. İlgili standardın sınır değerleri 3. Harmonik 2.3 Amper, 5. Harmonik 1.14 Amper, 7. Harmonik 0.77 Amper'dir. İstenmeyen harmoniklerin süzülmesi amacıyla devreye seri olarak bağlanan alçak geçiren süzgeç görevindeki $17 \mathrm{mH}$ endüktans ile devredeki 3. Harmonik 2.28 Amper, 5. Harmonik 0.73 Amper, 7. Harmonik 0.32 Amper olarak elde edilmiş ve ilgili standardın sınır değerlerini sağladığı gösterilmiştir. 
Analizlerin sonucunda devreye eklenen seri endüktansın alçak geçiren süzgeç görevi gördüğü, ilgili standardın sınır değerlerini sağladığı sonucu elde edilmiştir. Devreye eklenen giriş süzgeç yapısının endüktans değeri yükseltildikçe harmoniklerin genlik değerlerine ek olarak THD değerinin de düştüğü gözlemlenmiştir. Endüktans akımda faz kaymasına neden olduğu için reaktif güce neden olur. Neden olunan reaktif güç kaynak tarafında ki görünür gücü büyütür. $\mathrm{Bu}$ da akımın artmasına neden olur. Artan akım ise iletim yolarında kaybın artması sonucunu doğurur. Dolayısıyla standardın sınır değerlerini sağlayan en küçük endüktans değerinin saptanması kaynak tarafındaki görünür gücün, maliyetin ve fiziksel alan kaybının azaltılmasını için önemlidir.

\subsection{Tartışma}

$\mathrm{Bu}$ çalışma kapsamında DA/DA Alçaltıcı tip dönüştürücü devresinin TS-EN 61000-3-2 standardının sınır koşulları altında çalışabilmesi ve dolayısıyla elektromanyetik uyumlu olabilmesi için süzgeç yapısıyla güç kaynağından kesikli akım çekilmesinden kaynaklanan istenmeyen harmonikler bastırılmıştır. Çeşitli filtre değerleri denenmiş en uygun değer saptanmış ve elektromanyetik uyumlu olmayan filtresiz devre, filtre uygulamasıyla elektromanyetik uyumlu halde getirilmiştir.

\section{Sonuç}

Bu çalışmada alçaltıcı tip DA/DA dönüştürücünün harmonik akım yayınımları için sınır değerleri (faz başına cihaz giriş akımı<16 A) tanımlayan TS-EN 61000-3-2 standardına uyumlu hale getirilmesi için tasarım ve analiz gerçekleştirilmiştir. İlgili standart iletim yollu girişimleri belirli sınırlar içerisinde tutarak şebekeyi korumayı amaçlamaktadır. Böylelikle ilgili sınıftaki cihazların neden olduğu akım harmoniklerinin devrenin besleme kaynağında oluşturabilecekleri bozucu etkilerin ortadan kalkmasını sağlamaktadır. Çalışmada öncelikle DA/DA dönüştürücü analizi gerçekleştirilmiştir. Sonrasında DA/DA dönüştürücünün şebekeye olan bozucu etkilerini inceleyebilmek için DC gerilim kaynağı çıkartılıp yerine AA gerilim kaynağı ve AA/DA dönüştürücü yapısı eklenmiştir. Hedeflenen çalışma devrenin girişine uygulanan 324 Volt AA şebeke sinyalinin devrenin çıkışına 100 Volt DA olarak aktarabilmektir. Çıkış geriliminin 100 Volt değerinde sabitlenebilmesi için süzgeçsiz ve değişken süzgeçli devrelerde PWM üretecinin doluluk oranı değiştirilmiştir. Süzgeçsiz haliyle ilgili standardın Sınıf D harmonik akım sınır değerlerini sağlamayan alçaltıcı tip AA/DA dönüştürücü devre yapısına süzme amacıyla seri endüktans eklenmiştir. $2 \mathrm{mH}$ ile $17 \mathrm{mH}$ arasında farklı endüktans değeri denenmiş en uygun değer seçilerek tasarım son halini alıştır. En uygun süzgeç değerinin seçilmesinde tek sayıdaki harmoniklerin genlik değerlerinin TS-EN 61000-3-2 standardının gerektirdiği sınır değerlerin altında kalması zorunluluğu dikkate alınmıştır. Alçak geçiren süzgeç yapısının endüktans değerinin seçilmesinde harmoniklerin ilgili standart sınır değerlerini sağlamasının yanı sıra endüktif reaktanstan kaynaklanan empedans etkisi de dikkate alınmıştır. Bu nedenle ilgili sınır değerlerini sağlayan en küçük değerli endüktans seçilmiştir. Tasarımlar sonucunda devreye seri olarak bağlanan $17 \mathrm{mH}$ değerindeki endüktans ile ilgili standardın Sınıf D harmonik akım sınır değerlerini sağlayan devre modeli elde edilmiştir. Çalışmada standardın gereklerini sağlayabilen alçak geçiren süzgecin en küçük endüktans değeri $17 \mathrm{mH}$ olarak belirlenmiştir. Devrenin sinyallerinin süzgeç uygulanmadan önceki hali, alçak geçiren süzgeç eklenmiş hali ve ilgili standardın sınır değerleri karşılaştırıldığında süzgeç yapısı eklenmiş devrenin TS-EN 61000-3-2 elektromanyetik uyumluluk standardı kapsamındaki şebeke kaynağına bozucu etkisi bulunan harmoniklerin genliklerini bastırdığı, THD’yi düşürdüğü dolayısıyla standardın gerekliliklerini sağladığı gösterilmiştir.

\section{Teșekkür}

Değerli katkılarından dolayı Ersoy Kelebekler hocama teşekkürlerimi sunuyorum.

\section{Kaynakça}

Asadi, F., \& Abut, N.(2018). Güç Elektroniği Devrelerinin Matlab/Simulink ile Simülasyonu (1st ed.). Umuttepe Yayınlar1.

Bodur, H. (2010). Güç Elektroniği (1st ed.). Birsen Yayınevi.

Bogart, T.F., \& Brown, J.W. (1997). Experiments in Electronic Devices and Circuits (2nd ed.). Prentice Hall.

Costa, F., \& Laboure, E., \& Revol, B. (2014). Electromagnetic Compatibility in Power Electronics (1st ed.).Wiley.

International Electrotechnical Commission.(2002). Limits for Harmonic Current Emissions ( Equipment Input Current up to and Including 16A Per Phase), (IEC Standard No.610003-2).

Köseni, H., \& Yıldız, A. B. (2019). Geri dönüşlü DC-DC dönüştürücünün genelleştirilmiş düğüm denklemleri ile analizi. Politeknik Dergisi, 22(1), 179-184.

Patil, M. S., \& Patil, S. P. (2010). Single-phase buck-type power factor corrector with lower harmonic contents in compliance with IEC 61000-3-2. International Journal of Engineering Science and Technology, 2(11), 6122-6130.

Ürgün, S., Erfidan, T., \& Çoruh, N. (2008). DA-DA Buck Dönüştürücü Tasarımı ve Gerçeklenmesi. ElektrikElektronik-Bilgisayar Mühendisliği Sempozyumu (ELECO 2008), 358-361.

Yıldiz, A. B., \& Sabuncu, B. Harmonics in Power Systems and Filter Applications. Black Sea Journal of Engineering and Science, 2(4), 117-122. 